RESEARCH REPORT

\title{
Involvement in civil society groups: Is it good for your health?
}

\author{
A M Ziersch, F E Baum
}

J Epidemiol Community Health 2004;58:493-500. doi: 10.1136/jech.2003.009084

See end of article for authors' affiliations

.....................

Correspondence to: $\operatorname{Dr}$ A Ziersch, Department of Public Health, Flinders University, GPO' Box 2100, Adelaide SA 5001, Australia; anna.ziersch@ flinders.edu.au

Accepted for publication 12 September 2003

Study objective: To determine the involvement in civil society groups (CSGs) and the impact of this on health.

Design: Case study, cross sectional, self completion questionnaire, and semi-structured interviews. Setting: Residents in two suburbs in Adelaide, South Australia.

Participants: Every household (1038) received a questionnaire asking the adult with the next birthday to complete it. A total of 530 questionnaires were returned. Sixteen questionnaire respondents were also interviewed.

Main results: 279 (53\%) questionnaire respondents had been involved in a CSG in the past 12 months, $190(36 \%)$ in locally based CSGs, and $188(35 \%)$ in CSGs outside the area. Eleven of the 16 interviewees had been involved in a CSG. A path analysis examined the relation between demographic variables, CSG involvement, and mental and physical health, as measured by the SF-12. Physical health was negatively associated with CSG involvement and older age, and positively associated with working full time or part time and higher education level. Mental health was positively associated with older age, working full time or part time, and higher income but negatively associated with having a child under 18, speaking a language other than English and higher education level. Very few interviewees made a direct link between CSGs and positive individual health outcomes, though some positive community level outcomes were noted. More consistent were reports of the detrimental effects of CSG involvement on mental and physical health.

Conclusions: Involvement in CSGs was significant but not always positive for health. It is possible that CSG involvement is good for a community but not necessarily for the individual.

$\mathrm{T}$ he term "civil society groups" (CSGs) in this paper encompasses voluntary associations, groups, clubs, organisations, and societies. A growing debate on the role of social capital as a determinant of health has seen a focus on CSGs as an important part of community networks. Research sponsored by the World Health Organisation has suggested that CSGs can play a part in health development by making a positive impact on a community's health, ${ }^{1}$ but this research has not considered the impact on the health of the individuals involved. CSGs are usually assumed to be positive for health because they provide social contact for participants $^{2}$ and because they are seen as empowering to be involved in. ${ }^{3}$ This paper aims to describe involvement by the study respondents in an Australian sample in a range of CSGs; and to examine the relation between CSG involvement and health.

\section{Civil society groups and social capital}

Social capital is conceptually complex ${ }^{4}$ with much debate about its precise impact on health and what exactly it consists of. ${ }^{5}$ Two main schools of thought are represented by the work of Putnam and Bourdieu. ${ }^{6}$ Networks are seen as an essential aspect of social capital. Putnam's earlier formulations $^{78}$ distinctly privileged more formal networks or CSGs, which he refers to as voluntary organisations. ${ }^{9}$ CSGs are less central to Bourdieu's definition that focused more on the resources that accrue to people as a result of participation in social networks. Putnam argued that voluntary organisations were particularly rich environments for the development of social capital where people learn civic skills important for working together cooperatively in other ventures, and that where there are dense networks of civic participation, social capital is high.
Putnam's treatment of CSGs has been criticised on a number of grounds. It is argued that he failed to distinguish between types of groups and the different contributions they may make to social capital. ${ }^{10-12}$ Putnam has also been criticised for his exclusion of self help groups, ${ }^{13}$ national organisations and social movements, ${ }^{14-16}$ and more overtly political organisations such as trade unions, ${ }^{17}$ with arguments that these groups all make important contributions to social capital production. He has also been criticised for his privileging of horizontal civic organisations. Levi argues that vertical networks can also facilitate trust, reciprocity, and coordination. ${ }^{18}$ Other research on social capital that has considered involvement in CSGs has been criticised for using single item measures that do not capture the complexity of group membership. ${ }^{5}$

\section{Civil society groups and health}

There has been a substantial amount of work on the benefits of participation in CSGs. ${ }^{19}$ Prestby et al outline three main types of benefits: material benefits, such as wages and information; solidary benefits, such as socialising, status, group identification, and recognition; and purposive benefits, such as bettering the community, doing one's civic duty, and fulfilling a sense of responsibility. ${ }^{19}$ Others have seen these groups as mediating structures that counter the alienation of individualism implicit in market relation ${ }^{20}$ or that allow for identity formation in a diversified society. ${ }^{21}$ All of these benefits could be seen as directly or indirectly positive for health. However, there has been much less work on the costs of this participation.

Abbreviations: CSG, civil society group; PLS, partial least squares 
There has been a range of research that has explored the relation between CSGs, as part of social capital, and health outcomes. At an area level, Kawachi and colleagues considering 39 states in the US found a relation between per capita density of membership in voluntary associations and mortality. ${ }^{22}$ In Scotland, Ellaway and Macintyre found local association membership aggregated to area level was positively associated with health..$^{23}$ Campbell and Wood in a qualitative study in the UK found that areas with broader networks and higher civic engagement were those with better health outcomes. ${ }^{24}$

At an individual level, the findings have been less consistent. Joshi and colleagues found a positive link between "civic engagement", measured as involvement in voluntary work and attending a place of religious worship, and lower levels of symptoms of ill health. ${ }^{25}$ Rietschlin found that voluntary group membership was associated with lower depressive symptoms for both men and women aged 22-39, controlling for social support, personal mastery, and self esteem. ${ }^{26}$ Hyyppa and Maki found membership in a religious association was independently associated with good self rated health in a Finnish sample. ${ }^{27}$ However, while Ellaway and Macintyre found area level associations between local association membership and health, individual levels of membership were not apparent. ${ }^{23}$ Veenstra in Canada found few relations between participation in voluntary associations and self rated health. ${ }^{28}$ Rose looking at a Russian sample, also found no relation between membership in organisations and mental or physical health. ${ }^{29}$ Campbell and Wood found that informal networks were important to health but that formal networks in community groups were largely irrelevant to residents. ${ }^{24}$ Bush and Baum found that while social participation was related to health, civic participation was not although it was related to a sense of community control. ${ }^{30}$

In this way the link between CSG involvement and health, particularly at an individual level is far from clear. It also seems possible that relevance of CSG involvement may vary according to cultural context, with significant country variations in findings. ${ }^{2}$

\section{METHODS \\ Data collection \\ Case study area}

The data collection was undertaken in two suburbs (hereafter referred to as "the area") that are situated on the western fringes of central Adelaide, the capital of South Australia. Although they are two separate suburbs, they have a distinct joint identity, and a combined population of about 2500 residents (Australian census). The area has been an industrial one for many years and while there has been a significant movement of industry away from the area in recent years, substantial pockets remain and some contaminated land still awaits remediation. It has been a traditionally working class area and was once considered a "slum". It has had a historically strong ethnic mix with large numbers of Greek, Italian, and Yugoslavian immigrants moving into the area from the 1950s and immigrants from Vietnam in more recent times. The area also has a strong history of civic participation, often relating to resisting industrial expansion, and it was at the forefront of the cooperative housing movement, with a strong continuing cooperative housing presence in the area. In recent years the area has been undergoing a process of gentrification, as property is bought up by a new population of professionals and families who do not have traditional links to the area.

As part of the case study a questionnaire and interviews were undertaken in the area. The study was approved by the Social and Behavioural Research Ethics Committee at
Flinders University and conforms to the principles embodied in the Declaration of Helsinki.

\section{Questionnaire}

A self completion questionnaire was delivered to every household in the area. The "next birthday" sampling technique was used where the person in the household over the age of 18 who next had a birthday was asked to complete the questionnaire. Three follow up reminders (including one with a replacement questionnaire) were sent. Of the 1038 questionnaires delivered, 530 were returned, representing a response rate of $50.1 \%$

\section{Interviews}

An expression of interest form to participate in an interview was included with the questionnaire. Ninety three people returned this form. Sixteen were selected on the basis of their feelings of acceptance in the area. They were asked a range of questions about their experience of life in the area, participation in formal and informal networks, their civic and social participation, and health status.

\section{Data analysis}

\section{Questionnaire}

A latent variable path analysis was performed using partial least squares (PLS) regression procedures ${ }^{31} 32$ with the computer software PLSPATH 3.1 (Hamburg). Path analysis was utilised as it is able to deal with complex social variables and the interrelations between these variables. Latent variable path analysis entails the creation of "latent variables", or unobservable theoretical constructs, through their association with observable or "manifest variables". For example, a latent variable of HEALTH BEHAviours* can be created using measurable or manifest variables such as "exercise sessions per week", "alcohol consumption per week", and "tobacco consumption per week".

Path analysis using partial least squares was used here as it is particularly appropriate where there are many manifest and latent variables, where some or all of the manifest variables are categorical, where distributions are non-normal and under conditions of heteroscedasticity (that is, where the residuals on manifest and latent variables are correlated) (Falk RF, unpublished data).

In PLS path analysis the outer model indicates the relations between the latent variables and the observed or manifest variables (Falk RF, unpublished data). There are three types of relations between a latent variable and its associated manifest variable/s. In outward mode the latent variable is estimated in a way similar to that of a principal component, and factor loadings are used to represent the common variance among manifest variables. Factor loadings $\geqslant \pm 0.30$ are considered significant. In inward mode the latent variable is seen as being produced by manifest variables where the latent variable is estimated in a way similar to multiple regression analysis and regression weights are calculated. For a latent variable in the inward mode that has one categorical manifest variable with three or more categories (for example, AGE with six age range categories), each category can be converted into separate binary/dichotomous manifest variables (for example, 18-24 years, 25-34 years, etc) with the value of 0 and 1 . For each of these variables, respondents are then coded " 1 " if they belong to that particular age category and " 0 " if they do not. As for other types of regression analyses, one of the variables is then left out and made the dummy or comparison variable, against which the other variables are compared. This enables the manifest variables (in this case age categories) to be ranked in terms of the

* In the text latent variable names are written in small capitals. 
relation between the latent variable of AGE and another latent variable of interest. In unity mode the latent variable has only one associated manifest variable and both the weight and factor loading is always 1.00. For all three modes both weights and loadings generally range between +1 and -1 and the results are therefore in standardised form.

The inner model illustrates the hypothesised relations among the latent variables, $\uparrow$ and the strength of these relations is indicated by the regression weights for each path. PLS path analysis enables an estimation of the strength of both direct relations between latent variables, and also the indirect relations between latent variables through their common association with mediating variables.

In PLS path analysis the initial hypothetical model includes all paths between each latent variable with those latent variables coming after it in the model sequence. This model is then trimmed with paths between latent variables removed if the weights were less than $0.10 .^{33}$ However, for paths directly leading to the outcome variable, this criterion was relaxed to less than 0.08 , to allow for a consideration of less important but potentially interesting findings. Traditional significance testing is not appropriate in PLS path analysis largely because it cannot be assumed that all the variables in the model are normally distributed. Instead, the size of the estimated path coefficient is used to assess the strength of a variable's effect. In addition, using a jack-knife procedure, standard errors can be calculated by PLSPATH 3.1 and paths trimmed according to a "rule of thumb" where the jack-knife mean of a path must also be twice the jack-knife standard error, to remain in the inner model. To assess the strength of relations between the latent variables Cohen's ${ }^{33}$ effect size was also used where regression coefficients ranging from 0.10 to 0.29 were considered small effects, 0.30 to 0.49 considered medium effects, and greater than 0.50 considered large effects. Unless indicated otherwise the paths discussed represent small effect sizes in Cohen's terms. $\mathrm{R}^{2}$ values are also reported for each latent variable indicating the proportion of variance accounted for by the model.

Ten latent variables were used in the model (please see appendix for a full description of their associated manifest variables and outer model mode, available on the journal web site http://www.jech.com/supplemental). Six demographic variables were created as likely to be relevant to health and participation in CSGs: GENDER, AGE, CHILD STATUS, EDUCATION, WORK STATUS, INCOME, TENANCY, and YEARS AT ADDRESS. A CIVIL SOCIETY GROUPS latent variable was created using the number of types of local CSGs the person was involved with, and also those outside the area. The outcome variables of MENTAL HEALTH and PHYSicAl HEALTH were measured using SF-12 self report health measure mental and physical health summary scores. ${ }^{34}$ The analysis was undertaken separately for each of these summary scores.

\section{Interviews}

The interviews were analysed thematically with the assistance of NUD*IST covering themes relating to community/ neighbourhood life, involvement in CSGs, and health.

\section{RESULTS}

\section{Involvement in civil society groups}

Respondents were asked to indicate their membership in a number of types of CSGs over the past 12 months (table 1). Sporting, recreational, and hobby groups or clubs were the most common type of CSGs that people belonged to, with

TThis hypothetical model posits a sequential relation between variables such that the effect of a variable on all other variables that come after it can be considered. This means that two way relations between variables cannot be considered. almost a quarter of the sample being involved in this way. Work related groups, community groups, social action/ justice/lobby groups were fairly equally next popular, followed by school/education related groups, and coops. Political parties or political campaigns, local government and ethnic clubs were the least common forms of CSGs membership, with $5 \%$ or less of the sample being involved in these types of networks. A further $9 \%$ were involved in CSGs not specified by the other categories.

When considered together, these CSG memberships mean that over half of the respondents $(279,53 \%)$ were in at least one type of CSG, with almost a quarter in one type, $14 \%$ in two types, $8 \%$ in three, and very small percentages in four or more (fig 1). It should be noted that these statistics relate to the number of types of CSGs, not the number of CSGs themselves. In addition, these data refer to membership only, and do not give an indication of extent of involvement within the CSGs.

Of the interview sample of 16, 11 had been involved in a CSG in the past 12 months.

Questionnaire respondents were asked to indicate whether the CSGs they were involved in (specified as previously in table 1) were located locally or outside the area. Participation was similar with 190 (36\%) and 188 (35\%) in local CSGs or outside CSGs, respectively. This suggests that CSG participation is not necessarily concentrated in local groups, and that CSGs based outside area of residence provide important opportunities for interaction.

While local and outside CSG membership was similar in number, the nature of this involvement varied. As can be seen from table 2, social action/justice/lobby groups, community groups, and sports/recreational groups were the most common local groups, with over a quarter of those in local CSGs, in each of these types. However, sports and work related groups (such as professional or business association or trade union) were the most common CSG membership outside the area, with over a third of those in outside CSGs in these types.

Questionnaire respondents were also asked to name the actual CSGs they were in. Significantly, this information indicated that a number of those CSGs that were categorised as "local" were in fact outside the area. This might suggest that local membership figures are inflated, and if so, that CSG membership outside the local area is more common than that within. This also has interesting implications for the way that people define both "local" and "community".

\section{Relation between civil society group involvement and health}

To determine the relation between CSG involvement and health separate path analyses were conducted for PHYSICAL HEALTH and MENTAL HEALTH.

Table 1 Participation in civil society groups in the past 12 months

\begin{tabular}{ll}
\hline Group type & Number (\%) \\
\hline Sports, recreational or hobby group or club & $128(24)$ \\
Work related group & $86(16)$ \\
Community group & $78(15)$ \\
Social action, justice, or lobby groups & $73(14)$ \\
School or education related & $47(9)$ \\
Coops & $47(9)$ \\
Political party or political campaign & $28(5)$ \\
Local government & $23(4)$ \\
Ethnic club & $13(3)$ \\
Other group & $50(9)$ \\
\hline
\end{tabular}




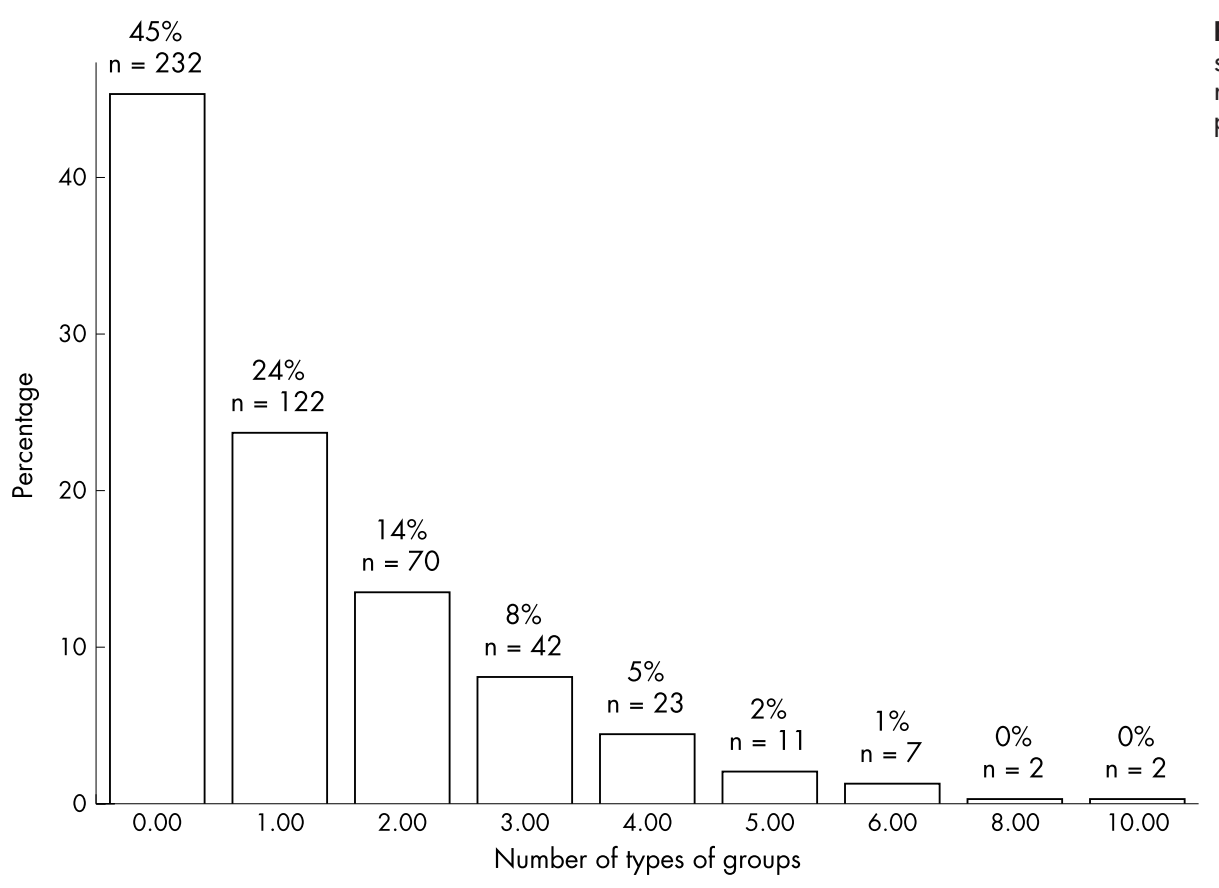

Figure 1 Total number of types of civil society groups that questionnaire respondents were involved in, in the past 12 months.

Four variables were significantly directly associated with PHYSICAL HEALTH, accounting for almost a quarter of the variance (see table 3 for the inner model direct and indirect effect results and table 4 for the outer model results). The inner model indicates that AGE was negatively directly associated with PHYSICAL HEALTH (MEDIUM EFFECT SIZE). For this inward mode variable the outer model ranks the age groups in terms of their physical health by comparing them with those aged 45-54 (the dummy or comparison variable). The outer model shows that the younger age groups have negative loadings and the older groups have positive loadings. In path analysis, where the inner model indicates a negative relation between a latent variable, " $\mathrm{A}$ ", and a latent variable, " $\mathrm{B}$ ", and the outer model indicates that latent variable " $\mathrm{A}$ " has a manifest variable that is negatively associated with it-the relation between that manifest variable and latent variable " $\mathrm{B}$ " becomes positive. Therefore where the latent variable of AGE is negatively associated with health and the manifest variables of the younger age groups have negative weights-it suggests a positive relation such that these younger age groups have better physical health than the older age groups. The indirect effects indicate that age was also indirectly negatively associated with physical health. That is, the older age groups were more likely to be associated with a variable that was negatively associated with physical health.

The inner model also indicates that WORK STATUS was positively directly associated with PHYSICAL HEALTH. The outer model indicates that those who were currently working full or part time had better physical health than those not currently working (the dummy variable). The inner model also indicates that EDUCATION was marginally positively associated with PHYSICAL HEALTH. The outer model loadings ranked those with no formal/primary only education as having the lowest physical health, with health increasing with educational achievement.

The variable, CIVIL SOCIETY GROUPS was negatively associated with PHYSICAL HEALTH, suggesting that greater CSG involvement was associated with worse physical health. The outer model indicated that for this outward mode variable the factor loadings for both local and outside CSG involvement were significant, although local involvement was somewhat stronger.

Six variables were significantly directly associated with MENTAL HEALTH, accounting for just over $10 \%$ of the variance (see table 5 for the inner model results and table $4 \ddagger$ for the outer model results). AGE was positively directly associated with MENTAL HEALTH (inner model), with the positive loadings of the older age groups (outer model) in this case indicating that they had better mental health than the younger age groups. Interestingly EDUCATION was directly negatively associated with mental health, with the rankings of the outer model this time indicating that mental health decreased with educational achievement. WORK STATUS was positively directly associated with mental health, with those working having better mental health. WORK STATUS was also positively indirectly associated with MENTAL HEALTH. INCOME was positively associated with MENTAL HEALTH, with mental health increasing with income level. There was also a marginally significant negative direct association between speaking a language other than English and MENTAL HEALTH. The outer model indicated that those from a non-English speaking background had poorer mental health compared with those speaking English only (the dummy variable). Likewise, CHILD STATUS was also marginally negatively directly associated with MENTAL HEALTH, with those having a child under 18 living in the house having poorer mental health, compared with those with no children in the house. CIVIL SOCIETY GROUPS was not significantly associated with MENTAL HEALTH.

The interviewees were also asked to assess the impact of CSG involvement on their health. They sometimes rolled this involvement together with other types of community participation (for example, informal networks, or involvement in civic actions). Overall, only a couple of the interviewees directly linked CSG involvement, or this "community participation" to positive individual health outcomes. One interviewee said:

¥The outer model relations for the demographic and civil society group variables were almost identical for both the physical health and mental health analyses, with only very minor variations in weights and loadings (at the second decimal place) and all overall relations remained the same. Therefore only the outer model for physical health is reported here. 
Table 2 Participation of questionnaire respondents in civil society groups, locally and outside the area, by group type

\begin{tabular}{lll}
\hline Network type & Locally (\% in local CSG) & $\begin{array}{l}\text { Elsewhere (\% in outside } \\
\text { CSG) }\end{array}$ \\
\hline School or education related & $22(12)$ & $27(14)$ \\
Community group & $51(27)$ & $36(19)$ \\
Ethnic club & $3(2)$ & $10(5)$ \\
Social action, justice, or lobby groups & $57(30)$ & $31(16)$ \\
Sports, recreational, or hobby group or club & $64(34)$ & $80(43)$ \\
Local government & $22(12)$ & $3(2)$ \\
Coops & $41(22)$ & $10(5)$ \\
Political party or political campaign & $24(13)$ & $9(5)$ \\
Work related group & $22(12)$ & $69(37)$ \\
Other group & $25(13)$ & $29(15)$ \\
\hline
\end{tabular}

I also think it [involvement in civil society groups] keeps people healthy, the social side of it and participation, learning new skills, and whatnot. It stimulates as well. And it maybe brings people together (Rachel).

However, there were indications that interviewees felt that such involvement was good for community life and here they mainly referred to local CSG involvement. It may be that individuals' involvement in CSGs may not directly have an impact upon their own health, as much as contributing to health promoting elements at a community level.

What was more clear from the interviews was the potentially detrimental health effects of participation in CSGs. For example, Beth referred to the impact of witnessing the difficult lives of those she helped when working with the charity the St Vincent De Paul Society:

...The negative is knowing that that sort of exists-You go out there and you can see some really bad things. You know, domestic violence and all of that.

Sometimes this lead to a cessation of involvement as it did for Elaine in relation to her involvement with a crisis telephone counselling service:

The person that was meant to come in on my shift at midnight didn't turn up, so I was alone for I think it was ten hours in this dark little bunker under the ground with this weirdo ringing me up all night telling me really disgusting things...Anyway it was just such an unpleasant experience, I kind of thought, what am I putting myself through this for?

Similarly, Rachel gave up her involvement as a support person for a troubled child, concerned for her physical safety:
Rachel: Sometimes I found it quite challenging. Sometimes I got sort of punched around a bit, which I didn't like. Interviewer: You mean physically?

Rachel: Yeah...And because of my injuries, I'm not prepared to risk that so I've decided to call it quits.

Christine, who has a history of mental illness, now living in public housing, previously lived in cooperative housing but left after difficulties with a coop member:

The treasurer was causing so much trouble and couldn't handle people with a mental disorder so she started attacking me and making it worse, so I got out.

Similarly, Rachel had also left a housing coop because of a lack of understanding of her health difficulties. Likewise, Barbara, who is currently in a housing coop, found meetings particularly difficult when the coop was going through a period of conflict:

Sometimes I was pretty stressed, that even when I came home from meetings I couldn't sleep for three days because it went through my head what went on (Barbara).

For Simon, reflecting on his involvement in music and theatrical CSGs, felt this participation to be very positive for his mental health, though he now considers that it may have aggravated his heart condition:

I always considered it [the involvement] was, at least psychologically, very positive. I felt a lot better for it. I felt I was meeting lots of people, and getting involved in lots of things was making me feel happier generally. Whether it was actually physically good for my health is another question. Maybe it wasn't. I don't know. But I can only say that in hindsight, because now having a heart problem, it

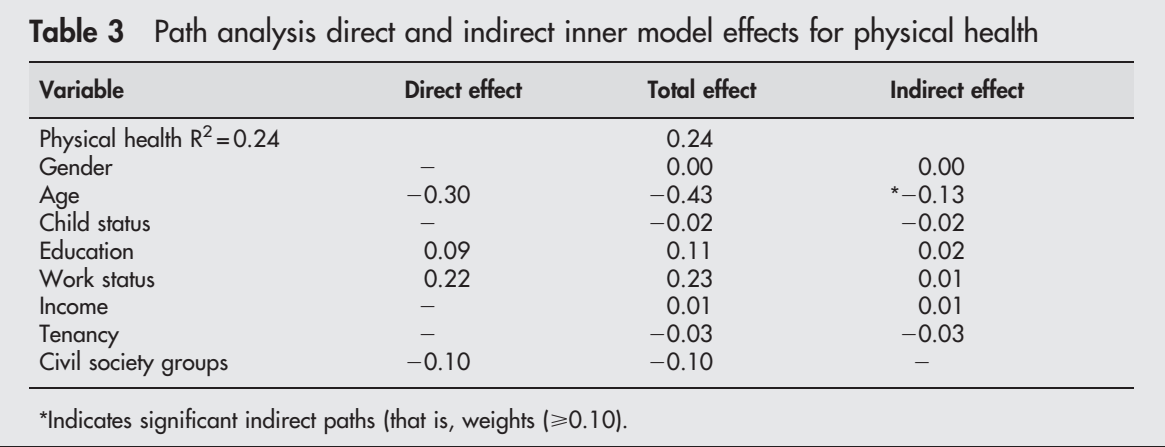




\begin{tabular}{|c|c|c|}
\hline Variable & Mode & Weight/loading* \\
\hline Gender & Unity† & \\
\hline Female & & 1.00 \\
\hline Male & & 0.00 \\
\hline Age & Inward $†$ & \\
\hline $18-24$ & & -0.06 \\
\hline $25-34$ & & -0.29 \\
\hline $35-44$ & & -0.18 \\
\hline $55-64$ & & 0.24 \\
\hline $65+$ & & 0.83 \\
\hline $45-54$ & & 0.00 \\
\hline Languages spoken & Unity & \\
\hline Other than English & & 1.00 \\
\hline English only & & 0.00 \\
\hline Child status & Unity† & \\
\hline Have children & & 1.00 \\
\hline Don't have children & & 0.00 \\
\hline Education & Inward $†$ & \\
\hline No formal/primary only & & -0.51 \\
\hline Technical/trade & & 0.37 \\
\hline Degree or higher & & 0.78 \\
\hline Secondary & & 0.00 \\
\hline Work status & Unity† & \\
\hline Working & & 1.00 \\
\hline Not working & & 0.00 \\
\hline Income & Unity & \\
\hline Own & & 1.00 \\
\hline Tenancy & Inward $†$ & \\
\hline Owner & & -0.46 \\
\hline Private rental & & -0.07 \\
\hline Public housing & & -0.12 \\
\hline Cooperative housing & & 0.81 \\
\hline Other & & 0.00 \\
\hline Years in area & Inward† & \\
\hline$<1$ & & -0.00 \\
\hline $4-9$ & & 0.15 \\
\hline $10+$ & & 1.06 \\
\hline $1-3$ & & 0.00 \\
\hline Civil society groups & Outward & \\
\hline In local area & & 0.89 \\
\hline Outside local area & & 0.69 \\
\hline
\end{tabular}

could be that it stirred it up a bit more in some cases. I may have overdone things. Sometimes I was involved in two choral performances coming up and a couple of plays all at the same time.

Similarly, Edith referred to her extended council related activities as negatively affecting her physical health:

Edith: It definitely did [negatively affect her health]. Well, the doctors, they all say that, that I've worked too hard and put too much into it.

Interviewer: You pushed it too hard?

Edith: We pushed too hard. I can remember at one stage, 'cos I have had back trouble, and my back was that bad.
And I was laying on the floor every now and again so I could get up and keep working...And I just thought, now it's not gonna beat me! And I just pushed myself, you know, too much.

In addition, to considering the impact of CSGs on health, some respondents noted the barriers to involvement of health difficulties themselves. Fifty one (10\%) of questionnaire respondents identified health reasons as a barrier to CSG involvement, and open-ended questionnaire responses and interviews supported this:

I currently have chronic fatigue, so find it hard to get involved in community issues and meetings-I go when I can (Quest.)

Table 5 Path analysis direct and indirect inner model effects for mental health

\begin{tabular}{lccc}
\hline Variable & Direct effect & Total effect & Indirect effect \\
\hline Mental health $\mathrm{R}^{2}=0.11$ & & 0.11 & -0.02 \\
Gender & - & -0.02 & -0.05 \\
Age & 0.21 & 0.16 & - \\
Languages spoken & -0.09 & -0.09 & -0.02 \\
Child status & -0.08 & -0.11 & 0.07 \\
Education & -0.13 & -0.06 & ${ }^{*} 0.11$ \\
Work status & 0.11 & 0.21 & - \\
Income & 0.20 & 0.20 & \\
\hline
\end{tabular}

*Indicates significant indirect paths (that is, weights $(\geqslant / 0.10)$. 


\section{Key points}

- There is growing debate about the role of social capital and civil society groups as health determinants.

- Over half the respondents had been involved in a civil society group in the past 12 months, with sports/ recreation groups the most popular type of group.

- Respondents were involved in civil society groups both locally and outside the study area.

- The quantitative analysis found a negative association between civil society group involvement and physical health, and no relation between civil society group involvement and mental health.

- The qualitative analysis found few respondents linked civil society group participation to positive individual health outcomes, but more commonly associated it with negative mental and physical health outcomes.

- Civil society group involvement may be detrimental to individual health for some, but could have positive health benefits at a community level.

Due to chronic migraines I participate less as my condition has worsened (Quest.)

There's three people... They go to bowling and having some meetings there. Old [neighbour], he asked me, 'Why don't you come along?'. I said, 'Look, I couldn't sit quiet for long period of time' [due to back injury] (Stanley).

Others related this to being too old:

I'm fifty-eight going on fifty-nine this year. I really would consider myself...just a little over the top with that. You know? You have to make the decision in your life at a certain age of your life as to what you really should and shouldn't be doing. And where you think the cut-off level would be-Well, I would suggest I will leave that now to people who are younger than myself (Frank)

I think as far as taking a REALLY active role in community things, we're beginning to feel we're getting a little bit past it, age-wise... (Simon, aged 69)

\section{DISCUSSION}

The results indicate significant involvement by the respondents in CSGs of varying types. Sports/recreation groups were the most popular form of CSG tie (Stone and Hughes ${ }^{35}$ also found this in an Australian context). Locally, community and social action type involvements were also important. This may reflect local issues garnering support in the area, and the historically strong role of community and resident action networks in the area. Respondents were also involved, to a similar extent, in CSGs outside the study area, again related to sports/recreation but also particularly to work related networks.

The quantitative analysis supported a strong literature regarding the social determinants of health. Work status was positively associated with both mental and physical health. Income was positively associated with mental health. Education was positively associated with physical health, but surprisingly it was negatively associated with mental health, though this was a marginal finding. This may relate to the history of the area, with some suggestion that people with mental health difficulties, but highly educated, had been attracted to the area by the availability of cooperative housing.§ Those speaking a language other than English had poorer mental health, as did those with children under 18 living at home. Age was positively associated with mental health, but negatively associated with physical health.

The quantitative analysis found a negative relation between CSG involvement and individual physical health. The qualitative analysis supported this finding for both physical and mental health. In this way, not only was CSG involvement not beneficial for health, but it could be argued that for some people it posed a health risk. The relation may, however, not be causal. It is possible that those with poorer physical health may be less likely to be working, and have more time for these involvements. The study area is recognised as one with high level of civic activity that is perceived to have benefits for the community. We tentatively suggest that certain types of CSG activity may be more beneficial for the health of the community collectively than it is for the people involved in the groups, supporting the area level studies quoted above. ${ }^{22-24}$

\section{Study limitations}

We note that the CSG measure, while more sophisticated than a number of other studies measuring CSG involvement, still only captured partial information about involvement in CSGs. It did not include information about the extent (for example, hours spent) or nature of involvement (for example, office bearer). Schudson ${ }^{36}$ argues that it is important to consider such measures of the "intensity" of group membership. We also suspect that involvement in sporting groups (with obvious health benefits) may be different to involvement in civic action and political groups. The last are likely to be more stressful.

In the quantitative analysis the path analysis model order meant that only one way relations between variables could be considered and that the impact of a variable could only be considered for variables following it. This means, for example, that it was not possible to consider the way that health impacted on CSG involvement.

The final models for physical and mental health accounted for $24 \%$ and $11 \%$ of the variance in scores, respectively. There are clearly other factors that are relevant to health that were not considered here. For example, we did not have any measures of "lifestyle" factors such as tobacco and alcohol consumption or regularity of exercise.

In conclusion, this research indicates that CSG involvement may not be beneficial for individual health, and that for the individuals involved there is some evidence that this involvement may in fact be detrimental for their own health. The relation is complex and while we were able to consider some of the elements of the relation between CSG involvement and health, there may be hidden differences between types of CSGs.

\section{ACKNOWLEDGEMENTS}

We gratefully acknowledge the invaluable assistance of Professor John Keeves in guiding the path analysis, I Gusti Ngurah Darmawan for his help in describing the technique, and Dr Colin MacDougall for his input into the study. We would also like to thank the study participants for their involvement in the research.

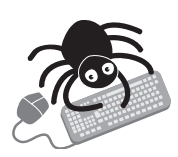

The appendix is available to view on the journal web site (http://www.jech.com/supplemetal).

$\S$ These suggestions were raised in informal interactions with a number of residents and community development workers in the area. 
Authors' affiliations

A M Ziersch, F E Baum, Department of Public Health, Flinders University, Adelaide, Australia

Funding: none.

Conflicts of interest: none declared.

\section{REFERENCES}

1 Baum F, Kahssay HM. Health development structures: an untapped resource. In: Kahssay HM, Oakley P, eds. Community involvement in health development: a review of the concept and practice. Geneva: WHO, 1999:96-113.

2 Trojan A, Hildebrandt H, Denke C, et al. The role of community groups and voluntary organizations in health promotion. In: Badura B, Kickbusch I, eds. Health promotion research: towards a new social epidemiology. Copenhagen: WHO Regional Publications European series no 37, 1991:441-66.

3 Kahssay HM, Oakley P. Community involvement in health development: a review of the concept and practice. Geneva: WHO, 1999

4 Schuller T, Baron S, Field J. Social capital: a review and critique. In: Baron S, Field J, Schuller T, eds. Social capital: critical perspectives. Oxford: Oxford University Press, 2000:1-38.

5 Macinko J, Starfield B. The utility of social capital in research on health determinants. Milbank Q 2001;79:387-427.

6 Baum F, Ziersch A. A glossary of social capital. J Epidemiol Community Health 2003;57:320-3.

7 Putnam R. Making democracy work: civic traditions in modern Italy. Princeton, NJ: Princeton University Press, 1993.

8 Putnam RD. The strange disappearance of civic America. The American Prospect 1996;24:34-48.

9 Putnam R. Bowling alone: the collapse and revival of American community New York: Simon and Schuster, 2000.

10 Skocpol T. Unravelling from above. The American Prospect 1996;25:20-5.

11 Stolle D, Rochon TR. Are all associations alike? American Behavioural Scientist 1998;42:47-66.

12 Verba S, Schlozman KL, Brady HE. The big tilt: participatory inequality in America. The American Prospect 1997;32:74-80.

13 Banks E. The social capital of self-help mutual groups. Social Policy 1997; autumn:30-8.

14 Minkoff DC. Producing social capital: National social movements and civil society. American Behavioral Scientist 1997;40:606-20.

15 Diani $M$. Social movements and social capital: a network perspective on movement outcomes. Mobilization 1997;2:129-47.

16 Foley M, Edwards B. Is it time to disinvest in social capital? Journal of Public Policy 1999;19:141-73.
17 Muntaner C, Lynch J, Oates G. The social class determinants of income inequality and social cohesion. Part 2: Presentation of an alternative model. Int J Health Serv 1999;29:715-32.

18 Levi M. Social and unsocial capital: a review essay of Robert Putnam's 'Making democracy work'. Politics and Society 1996;24:45-55.

19 Prestby J, Wandersman A, Florin F. Benefits, costs, incentive management and participation in voluntary organisations: a means to understanding and promoting empowerment. Am J Community Psychol 1990;18:117-49.

20 Couto RA, Guthrie CS. Making democracy work better: mediating structures, social capital and the democratic process. Chapel Hill: The University of North Carolina Press, 1999.

21 Giddens A. The third way and its critics. Oxford: Polity Press, 1999.

22 Kawachi I, Kennedy BP, Lochner K, et al. Social capital, income inequality, and mortality. Am J Public Health 1997;87:1491-8.

23 Ellaway A, Sally M. Social capital and self rated health: support for a contextual mechanism. [Letter]. Am J Public Health 1999:90:988.

24 Campbell C, Wood R. Social capital and health. London: Health Education Authority, 1999.

25 Joshi $H$, Wiggins RD, Bartley $M$, et al. Putting health inequalities on the map: does where you live matter, and why? In: Graham H, ed. Understanding health inequalities. Buckingham: Open University Press, 2000:143-55.

26 Rietschlin J. Voluntary association membership and psychological distress. $J$ Health Soc Behav 1998;39:348-55.

27 Hyyppä M, Mäki J. Individual-level relationships between social capital and self-rated health in a bilingual community. Prev Med 2001;32:148-55.

28 Veenstra G. Social capital, SES and health: an individual-level analysis. Soc Sci Med 2000;50:619-29.

29 Rose R. How much does social capital add to individual health? A survey study of Russians. Soc Sci Med 2000;51:1421-35.

30 Bush R, Baum F. Health, inequities, community and social capital. In: Eckersley R, Dixon J, Douglas R, eds. The social origins of health and wellbeing. Melbourne: Cambridge University Press, 2001:189-204.

31 Sellin N, Keeves JP. Path analysis with latent variables. In: Husen T, Postlethwaite TN, eds. The international encyclopedia of education. 2nd edn. Oxford: Pergamon, 1994:4352-9.

32 Sellin N. Partial least squares analysis. International Journal of Educational Research 1995;10:189-200.

33 Cohen J. A power primer. Psychol Bull 1992;112:155-9.

34 Ware JE, Kosinski M, Keller SD. SF-12: How to score the SF-12 physical and mental health summary scales. Boston, MA: The Health Institute, 1995.

35 Stone W, Hughes J. The nature and distribution of social capital: initial findings of the "families, social capital and citizenship survey". In: Competing visions. Sydney: National Social Policy Conference, 4-6 July 2001.

36 Schudson M. What if civic life didn't die? The American Prospect 1996;25:17-20 